\title{
Uji Kinerja dan Analisis Ekonomi Mesin Roasting Kopi (Studi Kasus di Taman Teknologi Pertanian Cikajang-Garut)
}

\author{
Performance Test and Economic Analysis of Roasting Coffee Machine \\ (Study Case in Agricultural Technology Park Cikajang-Garut)
}

\author{
Angelina Batubara, Asep Yusuf, Asri Widyasanti \\ Departemen Teknik Pertanian dan Biosistem, Fakultas Teknologi Industri Pertanian, Universitas Padjadjaran \\ Jl. Raya Bandung Sumedang km 21, Jatinangor 40600 \\ *E-mail: asriwidyasanti@gmail.com
}

Diterima: 22 Maret 2018; Disetujui: 23 April 2019

\begin{abstract}
ABSTRAK
Proses roasting kopi dibedakan menjadi 3 bagian yaitu light roast, medium roast, dan dark roast. Proses roasting yang dilakukan pada penelitian ini yaitu pada tingkatan medium roast dengan suhu $200-205^{\circ} \mathrm{C}$, dengan menggunakan mesin roasting kopi tipe SGR-5 seri 003 yang terdapat di Taman Teknologi Pertanian Cikajang. Analisis deskriptif dalam penelitian ini mencakup data kinerja mesin roasting kopi (suhu penyangraian, kadar air, laju penyangraian, efisiensi penyangraian, kebutuhan daya penggerak, kualitas hasil penyangraian, rendemen, dan konsumsi bahan bakar) dan data kinerja ekonomi (NPV, BCR, IRR dan Pay Back Period). Hasil pengamatan kinerja mesin diperoleh suhu penyangraian $192,4-202,4^{\circ} \mathrm{C}$ dan kadar air 3,09\%, sudah sesuai dengan SNI 7465:2008. Sedangkan efisiensi mesin 13,30\%, kebutuhan daya penggerak $126,28 \mathrm{~W}$, rendemen penyangraian $84,2 \%$, konsumsi bahan bakar $0,096 \mathrm{~kg} / \mathrm{jam}$, kadar abu 4,17\%, kapasitas teoritis 5 $\mathrm{kg} /$ proses, kapasitas aktual 0,752 kg/jam, dan energi spesifik 600,319 kJ/kg. Sementara itu, hasil analisis ekonomi diperoleh NPV Rp 23.574.251,66, BCR 1,17, IRR 80,69\% dan Pay Back Period dicapai pada tahun ke 1,18.
\end{abstract}

Kata kunci: analisis ekonomi; medium roast; roasting kopi; uji kinerja

\section{ABSTRACT}

Roasting process of coffee was divided into three parts: light roast, medium roast, and dark roast. Roasting process conducted in this research was at the level of medium roast with a temperature between $200-205^{\circ} \mathrm{C}$, by using the roasting machine type SGR-5 003 series in Cikajang Agricultural Technology Park. Descriptive analysis of this research covers the performance data of arabica coffee roasting machine (roasting temperature, moisture content, rate of roasting, roasting efficiency, the need for driving power, the quality of the roasted coffee, time for roasting, yield, and fuel consumption) and the economic feasibility analysis (NPV, BCR, IRR and Pay Back Period). The result performances of Arabica cofee roasting revealed that roasting temperature 192,4-202,4 ${ }^{\circ} \mathrm{C}$, water content $3.09 \%$, those were in accordance with SNI $7465: 2008$. While the roasting efficiency was $13.30 \%$, power requirement $126,28 \mathrm{~W}$, yield $84.2 \%$, fuel consumption $0.096 \mathrm{~kg} / \mathrm{hour}$, ash content of $4.17 \%$, theoretical capacity of $5 \mathrm{~kg} / \mathrm{process}$, actual capacity $0.752 \mathrm{~kg} / \mathrm{h}$, and specific energy $600,319 \mathrm{~kJ} / \mathrm{kg}$. Meanwhile, the results of economic analysis obtained NPV Rp 23.574.251,66, BCR 1.17, IRR 80.69\%, Pay Back Period Analysis achieved in 1.18 years.

Keywords: coffee roasting; economic analysis; medium roast; performance test

\section{PENDAHULUAN}

Kopi (Coffea sp.) merupakan komoditas ekspor penting Indonesia. Data ekspor kopi Indonesia ke berbagai negara senilai US\$ 588,329,553.00, walaupun ada catatan impor juga senilai US\$ 9,740,453.00 (Pusat Data dan Statistik Pertanian, 2006). Kopi merupakan salah satu hasil komoditi perkebunan yang memiliki nilai ekonomi yang cukup tinggi diantara tanaman perkebunan lainnya dan berperan penting sebagai sumber devisa negara. Kopi tidak hanya berperan penting sebagai sumber devisa melainkan juga merupakan sumber penghasilan bagi petani kopi di Indonesia (Rahardjo, 2012).

Keberhasilan agribisnis kopi di Indonesia didukung oleh banyak pihak yang terkait dalam proses produksi kopi, pengolahan, dan pemasaran komoditas kopi. Walaupun demikian upaya untuk meningkatkan produktivitas dan mutu kopi terus dilakukan agar kualitas kopi Indonesia tetap dapat bersaing di pasar dunia.
Untuk itu, teknologi budidaya dan pengolahan kopi yang meliputi pemilihan bahan tanam bibit kopi unggul, pemeliharaan, pemangkasan tanaman, pengendalian hama dan gulma, pemupukan yang seimbang, pemanenan, serta pengolahan pasca panen merupakan langkah strategi yang sangat dibutuhkan untuk menghasilkan kopi berkualitas tinggi. Pengolahan kopi sangat berperan penting dalam menentukan kualitas dan cita rasa kopi (Rahardjo, 2012).

Salah satu proses yang penting untuk mendapatkan aroma dan cita rasa kopi yang berkualitas adalah proses roasting kopi. Menurut Purnama (2016), proses roasting dibedakan menjadi 3 bagian, yaitu: light roast, medium roast, dan dark roast. Proses ini sangat menentukan cita rasa kopi yang akan dinikmati, sehingga dapat dikatakan bahwa tahapan ini merupakan proses yang sangat penting dibanding semua tahapan pengolahan kopi. Cita rasa kopi mampu divariasikan sesuai selera, tergantung pada bagaimana proses roasting ini dilakukan. 
Saat ini, pengolahan kopi tersebar luas di beberapa wilayah di Jawa Barat. Salah satunya di Taman Teknologi Pertanian Cikajang. Ketersediaannya mesin roasting kopi di Taman Teknologi Pertanian Cikajang dapat dimanfaatkan untuk mengolah green bean menjadi roasted bean yang dapat meningkatkan nilai kopi tersebut.

Penggunaan mesin roasting kopi di Taman Teknologi Pertanian Cikajang masih terhambat karena belum diketahui data kinerja mesin serta kelayakan ekonominya. Oleh karena itu perlu dilakukan penelitian mengenai uji kinerja mesin penyangrai (roasting) kopi dan analisis ekonomi.

\section{METODOLOGI PENELITIAN}

\section{Bahan dan Alat}

Bahan baku yang digunakan dalam penelitian ini adalah kopi arabika sebanyak $10 \mathrm{~kg}$ untuk 5 kali pengulangan. Kopi arabika ini berasal dari petani kopi Cikajang.

Alat yang digunakan pada penelitian adalah Mesin Roasting Kopi tipe SGR-5 (seri 003), timbangan digital, meteran, stopwatch, thermometer infrared, oven, tanur, cawan porselen, thermohigrometer, clampmeter.

\section{Metode}

Metode penelitian yang digunakan pada penelitian ini adalah metode penelitian dengan analisis deskriptif, yaitu melakukan pengukuran dan pengamatan terhadap kinerja mesin roasting kopi arabika dan analisis ekonomi. Data yang diperoleh dianalisis guna menentukan kelayakan fungsional maupun ekonomi dari mesin tersebut.

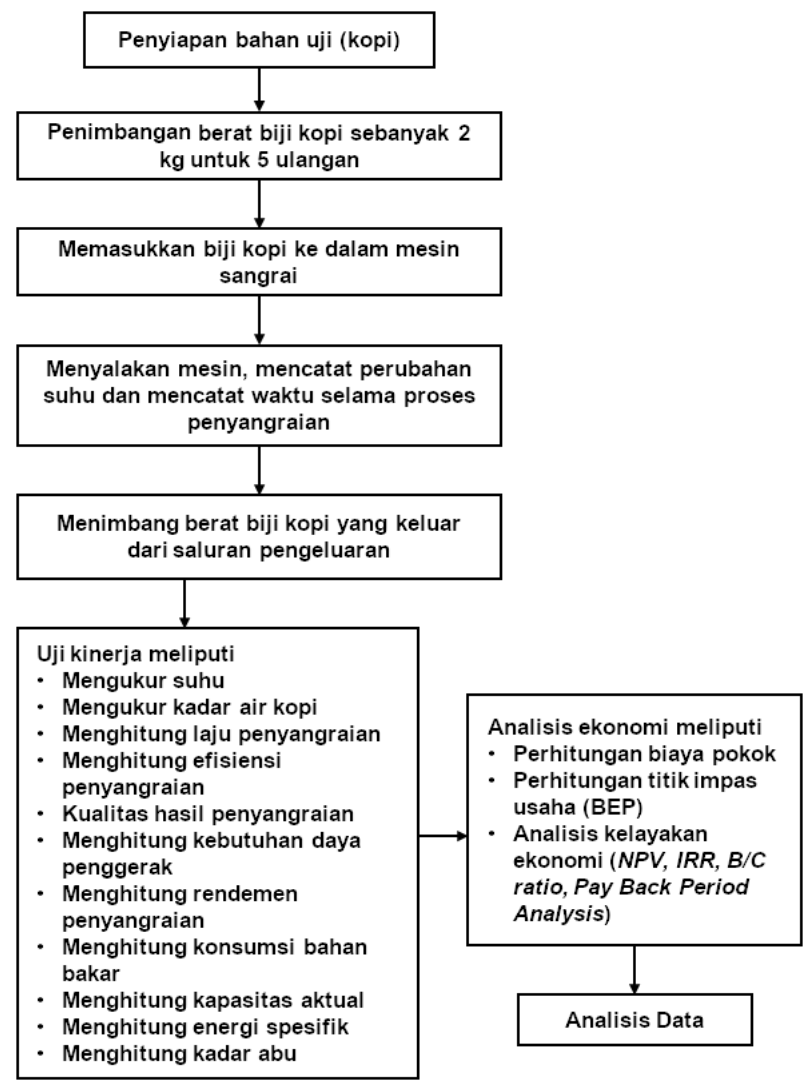

Gambar 1. Diagram Alir Penelitian

\section{Tahapan Penelitian}

Penelitian ini diawali dengan penyiapan bahan yaitu kopi, kemudian menyiapkan alat ukur yang akan digunakan, dilanjutkan dengan menimbang berat biji kopi sebanyak 2 $\mathrm{kg}$ untuk setiap ulangan, dilanjutkan dengan melakukan proses penyangraian hingga tingkat sangrai medium roast dengan menggunakan mesin roasting kopi. Adapun tahapan penelitian disajikan pada diagram alir peneitian Gambar 1.

Selama proses penyangraian, suhu diukur menggunakan thermokopel setiap 10 menit, kematangan sangrai ditandai dengan terjadinya crack pada biji kopi yang dapat diamati dengan mengambil sampel biji kopi melalui sample spoon.

\section{HASIL DAN PEMBAHASAN}

\section{Uji Kinerja}

Pengujian kinerja dapat memperlihatkan hasil kerja secara kualitas dan kuantitas dari mesin. Hasil pengujian kinerja mesin roasting kopi memperlihatkan bahwa kurang optimalnya penggunaan mesin tersebut. Hal ini dilihat dari kapasitas aktual mesin masih jauh dari kapasitas teoritisnya.

\section{Suhu Proses Penyangraian}

Proses penyangraian secara umum dapat dibedakan menjadi 3 bagian, yaitu light roast, medium roast, dan dark roast. Proses penyangraian tersebut dibedakan melalui suhu yang digunakan saat proses penyangraian berlangsung. Suhu proses penyangraian medium (medium roast) menurut Pusat Penelitian Kopi dan kakao (2012) yaitu $200-205^{\circ} \mathrm{C}$. Hasil pengukuran suhu saat proses penyangraian dilakukan dengan menggunakan mesin roasting tipe SGR-5 dapat dilihat pada Tabel 7 .

Tabel 1 . Suhu Penyangraian

\begin{tabular}{ccccc}
\hline Keterangan & $\begin{array}{c}\text { Suhu } \\
\text { Tabung } \\
\left({ }^{\circ} \mathrm{C}\right)\end{array}$ & $\begin{array}{c}\text { Suhu } \\
\text { Cerobong } \\
\left({ }^{\circ} \mathrm{C}\right)\end{array}$ & $\begin{array}{c}\text { Suhu } \\
\text { Kopi } \\
\left({ }^{\circ} \mathrm{C}\right)\end{array}$ & $\begin{array}{c}\text { Suhu } \\
\text { Ruang } \\
\left({ }^{\circ} \mathrm{C}\right)\end{array}$ \\
\hline \multirow{2}{*}{ Rata-rata } & 202,40 & 192,40 & 200,40 & 20,80 \\
$\pm 1,34$ & $\pm 8,79$ & $\pm 2,07$ & $\pm 0,83$ \\
\hline
\end{tabular}

Dari Tabel 1 dapat dilihat bahwa suhu rata-rata pada proses penyangraian yaitu $192,4-202,4^{\circ} \mathrm{C}$. Hal tersebut menunjukkan bahwa proses penyangraian yang dilakukan memiliki suhu sangrai medium roast, hal tersebut sesuai dengan hasil penelitian yang dilakukan Pusat Penelitian Kopi dan Kakao (2012).

\section{Kadar Air}

Pengukuran kadar air perlu dilakukan karena kopi hasil penyangraian menurut SNI 7465:2008 adalah sebesar 3\% basis basah. Pengukuran kadar air dilakukan dengan membandingkan massa awal biji kopi sebelum disangrai dengan massa akhir biji kopi setelah disangrai dari hasil pengeringan dengan menggunakan oven. Hasil perhitungan rata-rata kadar air roasted bean sebesar 3,09\% $\pm 0,06$ basis basah menunjukkan bahwa kadar air roasted bean sudah memenuhi standar kadar air yang diinginkan pada proses penyangraian. 


\section{Laju Penyangraian}

Laju penyangraian dihitung untuk mengetahui perubahan kadar air dan berat kopi selama proses penyangraian yang diukur setiap 10 menit. Pada periode penyangraian di antara 0 sampai 1 jam terlihat bahwa kadar air berubah dengan cepat. Kemudian pada menit selanjutnya hingga akhir penyangraian terlihat perubahan kadar air yang lambat. Sivetz dan Foote (1973) menyatakan bahwa pada tahap awal proses, energi panas yang tersedia di dalam ruang sangrai digunakan untuk menguapkan air. Kadar air biji kopi turun cepat pada awal penyangraian dan kemudian akan berlangsung relatif lambat pada akhir penyangraian.

Selama proses penyangraian berlangsung terjadi perpindahan panas dari silinder sangrai ke bahan dan juga perpindahan massa air. Panas yang mengakibatkan terjadinya perubahan massa air dari bahan dikarenakan adanya panas laten penguapan. Perubahan massa air ini terjadi ketika kandungan air pada bahan telah sampai pada kondisi jenuh, sehingga menyebabkan air yang terkandung di dalam bahan berubah dari fase cair menjadi uap. Perubahan ini terlihat nyata pada penurunan kadar air terhadap waktu yang ditunjukkan pada Gambar 2.

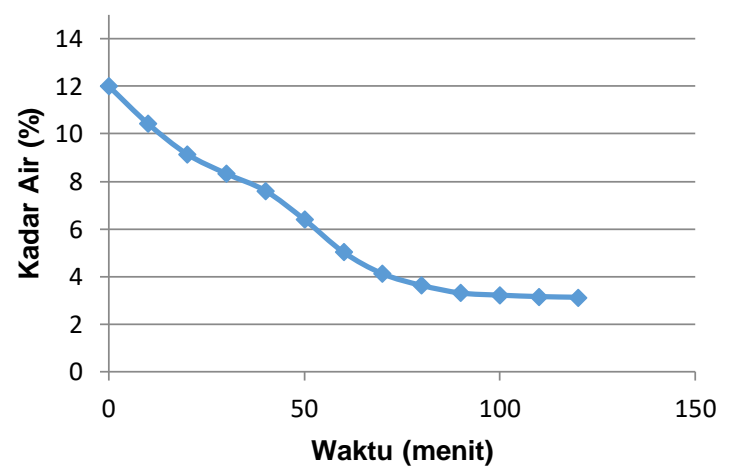

Gambar 2. Grafik Penurunan Kadar Air

Dari hasil perhitungan yang dilakukan, laju rata-rata penyangraian menggunakan mesin roasting kopi tipe SGR5 seri 003 sebesar $6,62 \% / j a m \pm 1,52$. Hasil tersebut tidak memenuhi standar yang ditetapkan SNI 7465:2008 yaitu 12\%/jam-18\%/jam. Grafik Laju Penyangraian disajikan di Gambar 3.

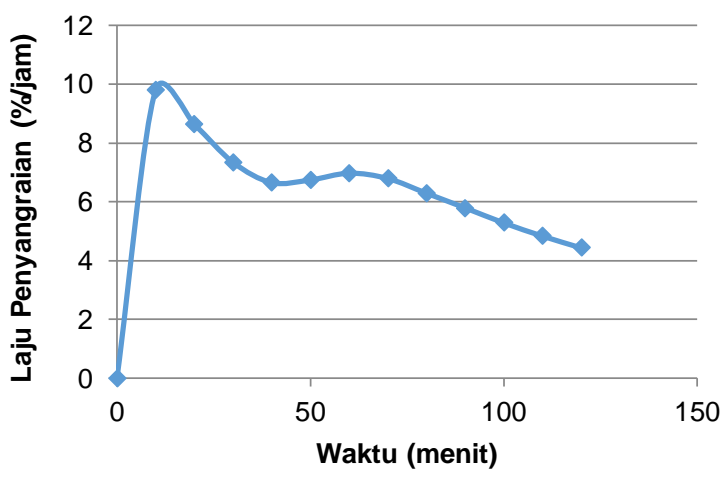

Gambar 3. Grafik Laju Penyangraian

\section{Efisiensi Penyangraian}

Efisiensi penyangraian dihitung untuk mengetahui apakah mesin yang digunakan di Taman Teknologi Pertanian Cikajang - Garut memiliki nilai efisiensi yang tinggi atau rendah. Dari hasil perhitungan yang dilakukan, didapat nilai efisiensi penyangraian sebesar $13,30 \%$. Nilai efisiensi dari penyangraian kopi dipengaruhi oleh massa bahan yang dapat diproses dengan mesin penyangrai. Efisiensi penyangraian berbanding lurus dengan kapasitas bahan yang dijadikan input. Namun pada penelitian ini, bahan yang dapat dijadikan input yaitu sebesar $2 \mathrm{~kg}$, masih jauh dari kapasitas teoritis mesin yaitu $5 \mathrm{~kg} /$ proses.

\section{Kebutuhan Daya Penggerak}

Kebutuhan daya motor listrik dihitung untuk mengetahui energi listrik yang diperlukan oleh motor listrik sebagai tenaga penggeraknya untuk melakukan penyangraian. Berdasarkan penelitian yang dilakukan dapat diketahui bahwa mesin saat beroperasi dengan beban memerlukan daya sebesar 126,28 \pm 1,20 Watt. Motor listrik yang digunakan memiliki daya sebesar 180 Watt, maka kebutuhan daya listrik mesin dapat dipenuhi oleh motor listrik yang digunakan.

\section{Kualitas Hasil Penyangraian}

Kualitas hasil penyangraian dilakukan untuk menilai keseragaman kopi sangrai. Parameter yang dinilai adalah warna, aroma, kadar air, dan kontaminasi asap. Hasil penyangraian kopi yang dilakukan dengan tingkat medium roast, dapat dilihat pada Gambar 4. Penilaian kualitas hasil penyangraian dapat dilihat pada Tabel 2 sebagai berikut:

Tabel 2. Kualitas Hasil Penyangraian berdasarkan Uji SNI 7465:2008)

\begin{tabular}{lccc}
\hline $\begin{array}{c}\text { Karakteristik } \\
\text { Fisik }\end{array}$ & $\begin{array}{c}\text { Sebelum } \\
\text { Disangrai }\end{array}$ & $\begin{array}{c}\text { Setelah } \\
\text { Disangrai }\end{array}$ & $\begin{array}{c}\text { Hasil } \\
\text { Penelitian }\end{array}$ \\
\hline Warna & Hijau muda & Coklat & Coklat \\
Aroma & Tidak ada & Ada & Ada \\
Kadar Air & $12 \%$ bb & $3 \%$ bb & $3,09 \%$ bb \\
Kontaminasi & Tidak ada & Tidak ada & Tidak ada \\
asap & & & \\
\hline
\end{tabular}

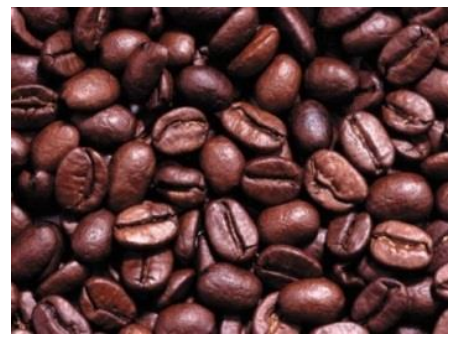

Gambar 4. Hasil Penyangraian

\section{Rendemen Penyangraian}

Rendemen penyangraian dihitung dengan membandingkan massa biji kopi yang telah disangrai dengan massa biji kopi yang dimasukkan ke dalam hopper. Hasil rendemen penyangraian kopi arabika berdasarkan perhitungan yang dilakukan adalah sebesar $84,2 \% \pm 2,7$ mesin yang baik memiliki nilai rendemen penyangraian yang mendekati $100 \%$.

\section{Konsumsi Bahan Bakar}

Konsumsi bahan bakar dihitung untuk mengetaui seberapa besar bahan bakar yang digunakan untuk melakukan proses penyangraian. Berdasarkan perhitungan yang dilakukan dapat diketahui bahwa rata-rata konsumsi bahan bakar untuk proses penyangraian yaitu sebesar 
$0,192 \mathrm{~kg} \pm 0,002$. Untuk melakukan proses penyangraian dengan bahan sebanyak $2 \mathrm{~kg}$, selama 150 menit membutuhkan bahan bakar berupa gas LPG sebanyak $0,192 \pm 0,002 \mathrm{~kg}$.

\section{Kadar Abu}

Kadar abu merupakan ukuran dari jumlah total mineral yang terdapat dalam bahan pangan. Penentuan kadar abu dapat digunakan untuk berbagai tujuan, antara lain untuk menentukan baik atau tidaknya suatu pengolahan, mengetahui jenis bahan yang digunakan, dan sebagai penentu parameter nilai gizi suatu bahan makanan (Danarti, 2006).

Berdasarkan pengukuran yang dilakukan, dapat diketahui bahwa kadar abu dari kopi hasil penyangraian rata-rata sebesar $4,171 \% \pm 0,37$. Menurut SNI 01-35422004 Kadar abu maksimal dari kopi sangrai adalah sebesar $5,00 \%$. Dapat dikatakan bahwa kopi hasil penyangraian menggunakan mesin penyangrai kopi tipe SGR-5 sudah memenuhi standar yang ditetapkan tersebut diatas.

\section{Kapasitas Teoritis}

Kapasitas teoritis, yakni kapasitas yang diperoleh dari asumsi teoritis. Kapasitas teoritis diketahui dari data spesifikasi mesin roasting yang digunakan. Berdasarkan spesifikasi dari mesin roasting kopi, nilai kapasitas teoritis mesin tersebut adalah $5 \mathrm{~kg} /$ proses.

\section{Kapasitas Aktual}

Kapasitas aktual mesin roasting dihitung berdasarkan jumlah biji kopi arabika yang dihasilkan dalam selang waktu tertentu. Perhitungan kapasitas aktual mesin roasting kopi dilakukan dengan menggunakan Persamaan 9. Hasil perhitungan kapasitas aktual mesin kopi sebesar 0,752 $\mathrm{kg} / \mathrm{jam}$ masih lebih kecil daripada kapasitas teoritis mesin penyangrai kopi $5 \mathrm{~kg} /$ proses.

\section{Energi Spesifik}

Menghitung energi spesifik penyangraian biji kopi bertujuan untuk mengetahui besarnya energi yang diperlukan untuk menyangrai biji kopi sebanyak $2 \mathrm{~kg}$. Berdasarkan perhitungan daya yang diperlukan untuk melakukan penyangraian maka dapat diperoleh pula energi spesifik penyangraiannya, dimana energi spesifik penyangraian diperoleh dari hasil bagi antara daya yang dihasilkan dengan kapasitas aktual penyangraian.

Energi spesifik penyangraian biji kopi rata-rata sebesar $600,319 \mathrm{~kJ} / \mathrm{kg}$. Secara teoritis, energi spesifik penyangraian akan meningkat jika kebutuhan daya listrik pada saat penyangraian meningkat sedangkan nilai kapasitas aktualnya semakin kecil.

\section{Analisis Ekonomi}

Analisis ekonomi menggunakan data biaya dari penelusuran pustaka, dan survei lapangan. Analisis ekonomi akan menghitung biaya pokok, titik impas usaha (BEP) dan analisis kelayakan ekonomi.

Penelusuran pustaka yang digunakan dalam analisis ekonomi untuk perhitungan biaya tetap adalah tingkat suku bunga bank per tahun sebesar 12\% (BRI, 2016), umur ekonomis mesin selama 5 tahun (sesuai dengan awal pemakaian mesin tersebut di TTP yaitu tahun 2016), nilai rongsok mesin 10\% dari harga mesin (Kastaman, 2004), biaya perawatan dan perbaikan sebesar $8 \%$ dari harga mesin (RNAM, 1995). Survei lapangan untuk perhitungan biaya tidak tetap adalah konsumsi energi listrik, bahan bakar, upah operator per jam. Survei lapangan lainnya yang digunakan adalah bahan baku yaitu biji kopi yang digunakan untuk proses penyangraian.

Tabel 3. Perbandingan Hasil Analisis Ekonomi Mesin Roasting Kopi dengan Standar Kelayakan Ekonomi

\begin{tabular}{ccccc}
\hline No & Parameter & Persyaratan & Hasil Uji & Keterangan \\
\hline 1 & $N P V$ & $N P V \geq 0$ & Rp 23.574.251,6 & Memenuhi \\
2 & $I R R$ & $I R R \geq M A R R$ & 80,69 & Memenuhi \\
3 & B/C Ratio & $B / C$ Ratio $\geq 1$ & 1,17 & Memenuhi \\
4 & Pay back period & Metode ini tidak digunakan perhitungan tetapi dianalis seberapa cepat investasi dapat kembali \\
\hline
\end{tabular}

\section{Biaya Pokok}

Biaya pokok dihitung dengan menjumlahkan biaya tetap dan biaya tidak tetap. Perhitungan biaya pokok penyangraian kopi per tahun berdasarkan perhitungan adalah sebesar Rp 33.770.071. Penerimaan kotor dalam satu tahun sebesar Rp 44.700.000,00. Biaya pokok dan penerimaan kotor dalam satu tahun akan digunakan dalam perhitungan titik impas usaha (BEP), dan analisis kelayakan ekonomi (NPV, BCR, dan Pay Back Period).

\section{Titik Impas Usaha (BEP)}

Titik impas usaha (BEP) dihitung berdasarkan besarnya produksi penyangraian kopi dalam setiap proses produksi, dimana besarnya total pendapatan sama dengan besarnya total pengeluaran (biaya) yang digunakan untuk proses penyangraian biji kopi per kilogram.

Dengan demikian, titik impas usaha dicapai setelah mesin menyangrai biji kopi sebanyak 18,491 kg. BEP dicapai setelah mesin roasting kopi beroperasi selama 0,19 tahun.

\section{Analisis Kelayakan Ekonomi}

Analisis kelayakan ekonomi dilihat dari tiga hal yaitu $N P V, I R R$, dan $B / C$ ratio. Proses penyangraian dilihat dari nilai NPV dinyatakan layak karena NPV penyangraian bernilai positif yaitu sebesar $R p$ 23.574.251,66 Sehingga memenuhi kelayakan ekonomi NPV $\geq 0$ (Blank et al, 2002). Nilai NPV yang bernilai positif disebabkan $B E P$ yang tercapai pada tahun pertama. Kondisi tersebut menyebabkan nilai pendapatan sekarang lebih besar dari nilai pengeluaran sekarang selama lima tahun masa pakai mesin sehingga nilai NPV bernilai positif. Persyaratan kelayakan ekonomi untuk $I R R$ jika nilai suku bunga $I R R \geq$ $M A R R /$ suku bunga bank (Blank et al, 2002). Hasil perhitungan IRR sebesar $80,69 \%$ sedangkan nilai suku bunga bank (MARR) yang berlaku adalah 12\% (BRI, 2016), maka proses penyangraian menggunakan mesin roasting kopi yang digunakan di TTP Cikajang memenuhi kelayakan ekonomi IRR.

Hasil perhitungan tersebut disebabkan oleh nilai NPV yang positif sehingga saat dicari suku bunga yang menyebabkan NPV bernilai nol atau negatif menjadi lebih besar dari suku bunga bank atau MARR. Persyaratan kelayakan $B / C$ ratio jika nilai $B / C$ ratio $\geq 1$ maka dapat 
dikatakan layak. Pada perhitungan $B / C$ ratio dari proses penyangraian sebesar 1,17 Nilai tersebut sudah memenuhi kelayakan ekonomi $B / C$ ratio dan menunjukkan bahwa usaha tersebut mempunyai keuntungan (benefit) lebih besar dari biaya produksi (cost). Perhitungan kelayakan metode Pay Back Period, tercapai pada tahun ke-1,18. Perbandingan antara hasil perhitungan kelayakan ekonomi dengan standar kelayakan ekonomi dapat dilihat pada Tabel 3 Hasil perbandingan menyatakan seluruh kriteria kelayakan ekonomi terpenuhi. Kondisi ini dapat dicapai bila seluruh data penelusuran pustaka dan survei lapangan dalam perhitungan analisis ekonomi dapat dipenuhi.

Perhitungan analisis kelayakan ekonomi diatas merupakan perhitungan yang dilakukan dengan kondisi yang terdapat di Taman Teknologi Pertanian Cikajang. Berikut adalah perbandingan analisis kelayakan ekonomi apabila di Taman Teknologi Pertanian Cikajang dilakukan penambahan hari kerja yaitu 5 hari kerja dalam satu minggu untuk mengoptimalkan nilai ekonomi dari mesin roasting kopi. Hasil dari perhitungan analisis kelayakan ekonomi dapat dilihat pada Tabel 4.

Tabel 4. Perbandingan Hasil Analisis Ekonomi Mesin Roasting Kopi dengan Standar Kelayakan Ekonomi (5 hari kerja)

\begin{tabular}{ccccc}
\hline No & Parameter & Persyaratan & Hasil Uji & Keterangan \\
\hline 1 & $N P V$ & $N P V \geq 0$ & Rp 416.861.038,77 & Memenuhi \\
2 & $I R R$ & $I R R \geq M A R R$ & 128,16 & Memenuhi \\
3 & B/C Ratio & $B / C$ Ratio $\geq 1$ & 2,15 & Memenuhi \\
\hline
\end{tabular}

\section{Uji Hedonik}

Analisis sensori kopi dilakukan dengan menyajikan kopi dalam bentuk roast bean, bubuk kopi dan seduhan murni (tanpa bahan tambahan) yang akan menghasilkan rangsangan kimia dan psikis kepada responden. Hasil pengukuran dari 15 orang panelis terlatih berupa reaksi psikologis dalam bentuk sensasi dan persepsi yang bersifat subyektif yang ditentukan oleh panelis sendiri (Mulato \& Suharyanto, 2012). Parameter analisis sensori yang diujikan adalah warna, aroma, rasa, dan body dari roast bean, bubuk kopi dan seduhan murni. Nilai persentase warna roasted bean, bubuk kopi, seduhan kopi berturutturut disajikan di Gambar 5, Gambar 7, dan Gambar 9.

\section{Roasted Bean}

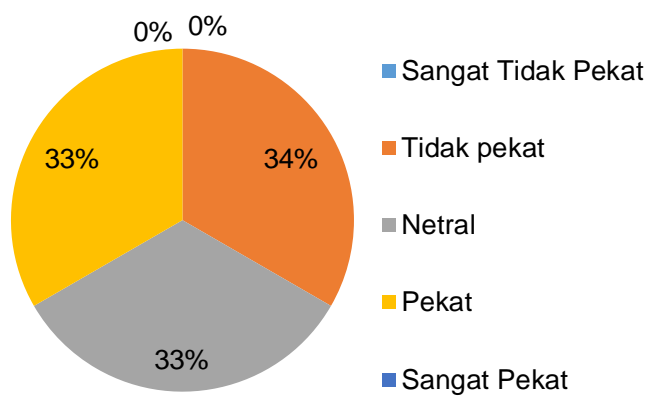

\section{Gambar 5. Persentase Warna Roasted Bean}

Berdasarkan roasted bean yang disajikan, 34\% panelis menilai bahwa warna dari biji kopi tersebut tidak pekat. Warna dari roasted bean tersebut dinilai dengan membandingkan warna roasted bean hasil penelitian dengan tingkatan warna penyangraian kopi. Nilai persentase aroma roasted bean, bubuk kopi, seduhan kopi berturut-turut disajikan di Gambar 6, Gambar 8, dan Gambar 10.

Aroma merupakan salah satu atribut terpenting dalam menilai kualitas kopi sangrai. Aroma kopi yang ditangkap oleh indera penciuman merupakan hasil penguapan senyawa organik volatile (Mulato \& Suharyanto, 2012). Berdasarkan penilaian aroma kopi sangrai yang disajikan, $80 \%$ panelis menilai bahwa aroma kopi netral, yang berarti aroma yang dirasakan tidak pekat.

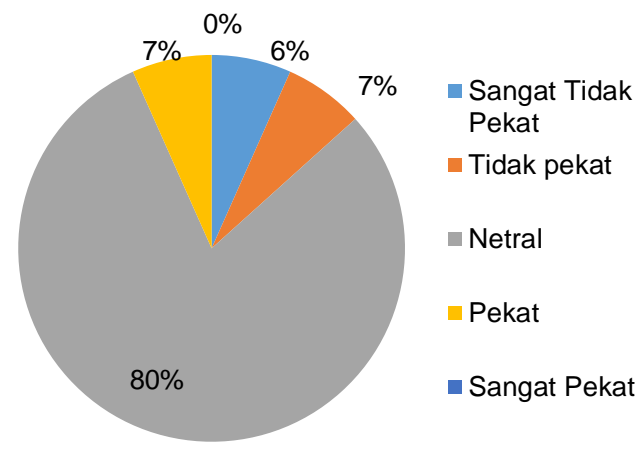

Gambar 6. Persentase Aroma Roasted Bean

\section{Bubuk Kopi}

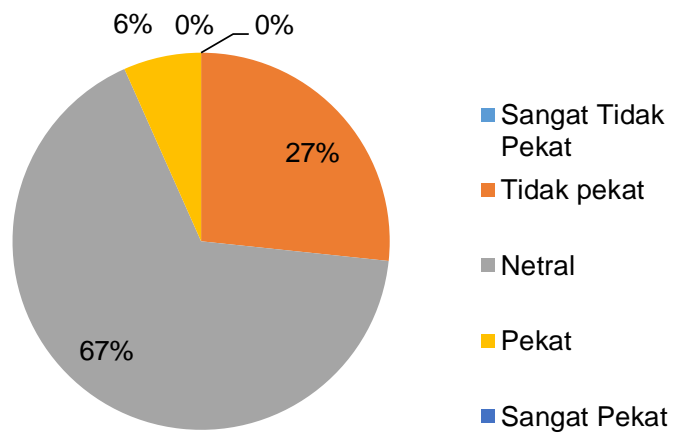

Gambar 7. Persentase Warna Bubuk Kopi

Berdasarkaan bubuk kopi yang disajikan, 67\% panelis menilai bahwa warna dari bubuk kopi hasil penelitian memiliki warna yang netral. Warna netral yang dimaksud adalah warna yang sudah sesuai dengan kopi medium roast. 


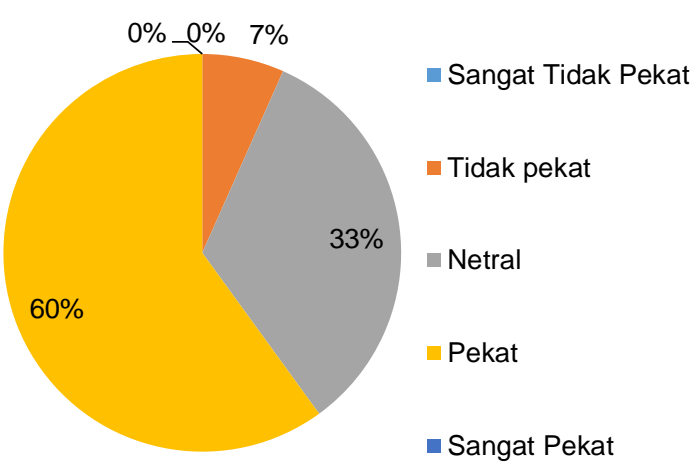

Gambar 8. Persentase Aroma Bubuk Kopi

Berdasarkan bubuk kopi yang disajikan, 60\% panelis menilai bahwa bubuk kopi memiliki aroma yang pekat. Aroma pekat yang dihasilkan kopi bubuk dikarenakan adanya proses grinding yaitu pengecilan ukuran kopi. Itulah sebabnya bubuk kopi memiliki aroma yang lebih pekat dari roasted bean.

\section{Seduhan Kopi}

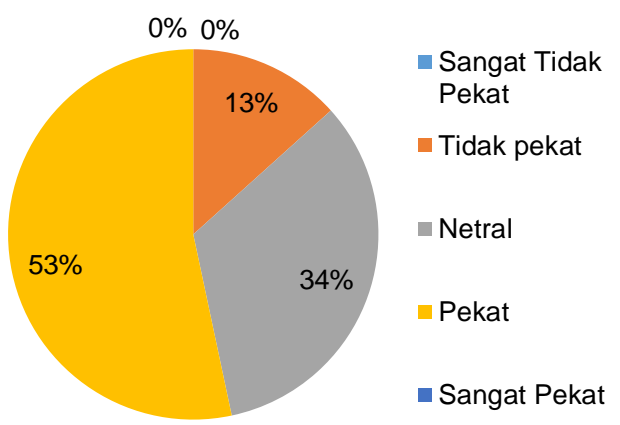

Gambar 9. Persentase Warna Seduhan Kopi

Indera penglihatan merupakan sensor paling awal untuk mengetahui kualitas kopi seduhan secara kualitatif yang ditinjau berdasarkan warna. Dari 15 panelis yang memberi penilaian terhadap seduhan kopi, 53\% menyatakan bahwa warna dari seduhan kopi arabika yang disangrai pada tingkatan medium roast memiliki warna yang pekat.

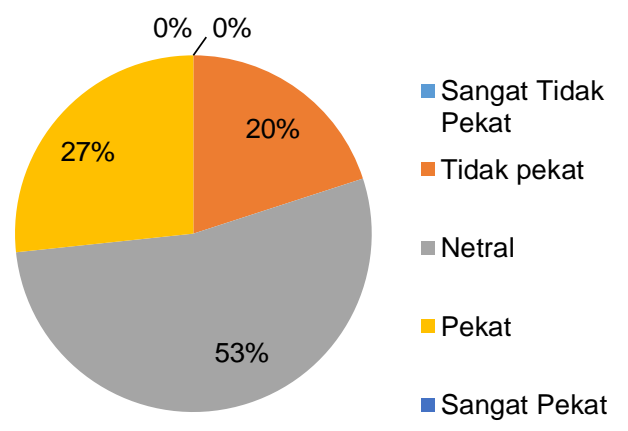

Gambar 10. Persentase Aroma Seduhan Kopi

Untuk mengetahui aroma dari seduhan kopi, arah gerakan sendok dimulai dari depan indera penciuman lalu menjauhi hidung, hal ini dimaksudkan untuk menangkap aroma yang keluar bersama kepulan uap yang keluar dari seduhan kopi tersebut. Berdasarkan aroma kopi seduhan yang disajikan, 53\% panelis menilai bahwa seduhan kopi memiliki aroma yang netral. Nilai Persentase rasa seduhan disajikan Gambar 11.

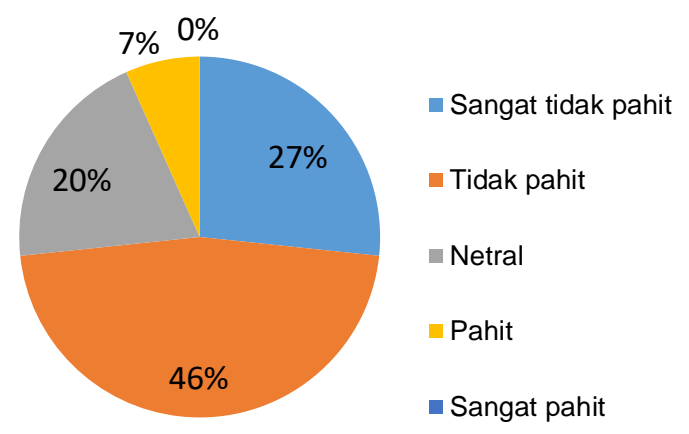

\section{Gambar 11. Persentase Rasa Seduhan Kopi}

Selain aroma, rasa juga berperan dalam menentukan kualitas seduhan kopi yang pengukurannya menggunakan indera pengecap. Rasa yang dihasilkan berasal dari senyawa organik non-volatile dan mineral dalam fase cair yang bisa dirasakan oleh indera pengecap (Mulato \& Suharyanto, 2012). Berdasarkan seduhan kopi yang disajikan $46 \%$ panelis menilai bahwa rasa seduhan kopi tidak pahit. Hal tersebut dikarenakan pada jenis kopi arabika yang disangrai pada tingkatan medium roast, akan menimbulkan rasa yang cenderung asam. Nilai Persentase body seduhan disajikan Gambar 12.

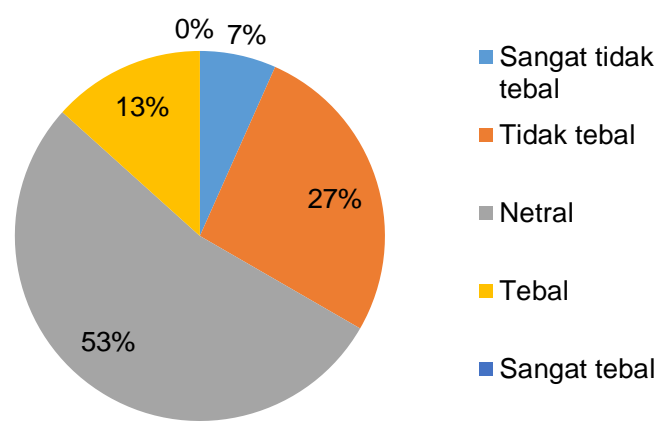

Gambar 12. Persentase Body Seduhan Kopi

Tekstur kopi terkait densitas dan viskositas yang di dalam kopi sering disebut dengan body. Di dalam mulut, body sering digambarkan seperti kehalusan dan kepekatan kopi yang dirasakan oleh permukaan lidah. Sensasi body ditimbulkan oleh keberadaan senyawa lipida dan polisakarida yang terlarut dalam larutan kopi (Mulato \& Suharyanto, 2012). Berdasarkan penilaian body seduhan kopi disajikan, sebanyak $53 \%$ panelis menilai bahwa body dari kopi tersebut tidak tebal, yang artinya rasa yang tertinggal di mulut ketika kopi tersebut diminum tidak melekat terlalu lama.

Dari hasil uji sensori atau hedonik di atas dapat disimpulkan bahwa massing-masing kopi memiliki cita rasa yang berbeda hal ini tergantung dari spesies, ketinggian tempat tanam dan drying process-nya. Menurut Purnama (2016) dalam artikel yang terdapat di Dinas Perkebunan Provinsi Jawa Barat, karakter kopi dari Jawa Barat memiliki body yang tidak tebal dengan rasa yang cenderung lebih asam, hal ini dipengaruhi ketinggian tempat tanam dan proses pasca panen yang dilakukan. 


\section{KESIMPULAN}

Berdasarkan hasil penelitian yang telah dilakukan maka dapat disimpulkan bahwa Hasil uji kinerja terhadap mesin roasting kopi menujukkan bahwa mesin yang terdapat di Taman Teknologi Pertanian Cikajang belum layak digunakan, hal tersebut karena adanya parameter uji yang belum memenuhi SNI 7465:2008, sedangkan hasil analisis ekonomi mesin roasting kopi sudah memenuhi parameter yang digunakan antara lain nilai NPV mesin roasting kopi adalah $\operatorname{Rp} 23,574,251.66$ Hasil tersebut memenuhi syarat kelayakan NPV, IRR mesin penyangrai kopi yaitu $80,69 \%$ Hasil tersebut memenuhi syarat kelayakan IRR, B/C Ratio mesin penyangrai kopi yaitu 1,17 Hasil tersebut memenuhi syarat kelayakan $B / C$ Ratio. Untuk periode pengembalian modal, investasi tersebut memperoleh keuntungan pada tahun ke-1,18.

\section{DAFTAR PUSTAKA}

Blank, L \& Tarquin, A. (2002). Engineering Economy. New York, NY: McGraw-Hill

Danarti, N. S. (2006). Kopi Budidaya dan Penanganan Pasca Panen. Jakarta, Indonesia: Penebar Swadaya.

Mulato, S \& Suharyanto, E. (2012). Kopi, Seduhan dan Kesehatan. Jember, Indonesia: Pusat Penelitian Kopi dan Kakao Indonesia

Purnama, S. (2016). Proses dan Tingkatan Roasting Kopi. Retrieved from URL: http://disbun.jabarprov.go.id/index.php/artikel/detailarti kel/121 (2017, 20 ${ }^{\text {th }}$ February).

Pusat Data dan Statistik Pertanian. (2006). Statistik Perkebunan. Departemen Pertanian.

Rahardjo, P. (2012). Panduan Budidaya dan Pengolahan Kopi Arabika dan Robusta. Jakarta, Indonesia: Penebar Swadaya

RNAM (Regional Network Agriculture Machiner) Test Codes and Procedures for Farm Machinery. (1995). Unindo. United State of America.

Sivetz, M \& Foote, H. E. (1973). Coffee Processing Technology Vol.I. The Avi Publishing Company Inc.

SNI. (2004). Syarat Mutu Kopi Bubuk (SNI 01-3542-2004). Jakarta, Indonesia: Badan Standarisasi Nasional.

SNI. (2008). Mesin Sangrai Kopi dan Kakao Tipe Silinder Datar Berputar, Syarat Mutu dan Cara Uji (SNI 7465:2008). Jakarta, Indonesia: Badan Standarisasi Nasional.

Najiyati, S \& Danarti. (2004). Budidaya Tanaman Kopi dan Penanganan Pasca Panen. Jakarta, Indonesia: Penebar Swadaya.

Suharyanto, E. (2006). Pengolahan Biji Kopi. Pusat Penelitian Kopi dan Kakao Indonesia. 